\title{
$\beta$-Cyclodextrin Covalently Functionalized Single-Walled Carbon Nanotubes: Synthesis, Characterization and a Sensitive Biosensor Platform
}

\author{
Yong Gao ${ }^{1}$, Yu Cao ${ }^{1}$, Guiling Song ${ }^{1}$, Yiming Tang ${ }^{1}$, Huaming Li ${ }^{12^{*}}$ \\ ${ }^{1}$ College of Chemistry, Xiangtan University, Xiangtan, China; ${ }^{2}$ Key Laboratory of Polymeric Materials and Application Technology \\ of Hunan Province, Key Laboratory of Advanced Functional Polymeric Materials of College of Hunan Province, and Key Lab of \\ Environment-Friendly Chemistry and Application in Ministry of Education, Xiangtan University, Xiangtan, China. \\ Email: *lihuaming@xtu.edu.cn
}

Received July $30^{\text {th }}, 2011$; revised August $18^{\text {th }}, 2011$; accepted September $1^{\text {st }}, 2011$.

\begin{abstract}
In this study, we presented the preparation of $\beta$-cyclodextrin $(\beta-C D)$ covalently functionalized single-walled carbon nanotubes (SWCNTS) and its application in modifying the solid glass carbon electrode (GCE). Cyclic voltammetry (CV) method was employed to evaluate the performance of the modified GCE. Solubility experiment indicated the conjugation of SWCNTs and $\beta$-CD, SWCNTs- $\beta-C D$ with $8 \mathrm{wt} \% \beta$-CD content could be well dispersed in water. High-resolution transmission electron microscopy (HRTEM) demonstrated that the aggregated SWCNTs bundle were effectively exfoliated to small bundle, even individual tube. The $\beta-C D$ component was grafted on the side walls as well as tips of SWCNTs, and the grafted $\beta$-CD component was not uniformly coated on the surface of SWCNTs. The CV measurements indicated the performance of the GCE modified by SWCNTs- $\beta$-CD was better than that of the GCE modified by the hybrid of $S W C N T s / \beta-C D$, where ascorbic acid $(A A)$ and uric acid $(U A)$ were selected as a prelimiltary substrate to evaluate it. The enhanced performance of the modified GCE should be ascribed to the integration of the excellent electrocatalytic property of SWCNTs with the inclusion ability of $\beta-C D$ to analyte molecule.
\end{abstract}

Keywords: Single-Walled Carbon Nanotubes (SWCNTs), $\beta$-Cyclodextrin $(\beta-C D)$, Electrochemical Sensor, Covalently

\section{Introduction}

Since the landmark paper on carbon nanotubes (CNTs) in 1991 by Iijima [1], they have attracted great interdisciplinary interest due to the extraordinarily electrical, optical, and mechanical properties that CNTs possess $[2,3]$. Nowadays, CNTs have the potential of being transformed into new materials that will traverse a wide range of applications, such as sensors, nanoelectronics, biomedical devices, and high-strength fibers [4-7]. However, aggregated large nanotube bundles were insolubility in routine solvent, which makes it difficult to manipulate and utilize CNTs $[8,9]$.

Two strategies, including noncovalent and covalent modification, have been developed to modify the CNTs to overcome the solubility limitations [10-16]. In the cased of the noncovalent modification strategy, a rather limited surfactants and compounds with benzene ring or condensed aromatic ring are usually used to disperse the CNTs bundle. The virtues of noncovalent modification lie in the maintaining of the nanotube's electronic structure and its relatively simple process [17]. With respect to noncovalent modification, covalent functionalization of CNTs provides a broad space in singling out the species of compound, for a broad range of functional groups could be incorporated onto the surface of CNTs by more versatile modification approaches. Covalently functionalized CNTs demonstrated wide applications in many fields, such as in catalytic and biological applications etc [18-22]. For example, Neelgund, et al. [18] reported the synthesis of poly(lactic acid) functionalized CNTs-Pd nanocatalyst by covalent grafting of poly(lactic acid) onto CNTs and subsequent deposition of Pd nano- particles. The nanocatalyst demonstrated more effective activity in the promotion of Heck cross-coupling reaction between aryl halides and n-butyl acrylate. Karousis, et al. 
[22] reported that the preparation of water-soluble peptidomimetics covalently grafted carbon nanotubes. The prepared peptidomimetic functionalized CNT conjugates showed extremely advantageous in the inhibition of inflammation or malignancy and potential future biological applications in the area of drug delivery systems.

Cyclodextrins (CDs) are cyclic oligosaccharides with $\mathrm{D}-(+)$-glucose as the repeating unit coupled by $1,4-\mathrm{a}-$ linkages. $\alpha-, \beta$-, and $\gamma$-CDs are commonly available forms which consist of 6,7 , and 8 glucose units, respectively. The most characteristic property of CDs is their remarkable ability to form inclusion complexes with a wide variety of guest molecules due to their different cavity sizes. This property endowed CDs many widespread applications not only in pharmaceutical chemistry, food technology, analytical chemistry, chemical synthesis, and catalysis [23-27], but also for constructing molecular devices and machines [28-32]. Therefore, the combination of $\beta$-CD and CNTs is sure to generate significant and interesting object for supramolecular chemistry, biomedicine and nanodevice construction. However, most studies were focused on the hybrids of $\beta$-CD/CNTs due to its easy operation, and the studies concerning the preparation of $\beta$-CD covalently functionalized CNTs and its application were rare except for several reports [17,33-37].

Herein, we presented the preparation of $\beta$-CD covalently functionalized SWCNTs by a reaction sequence involving oxidation and amidation reaction. The obtained conjugation of SWCNTs and $\beta$-CD, SWCNTs- $\beta$-CD showed an excellent stability in pure water. And then, SWCNTs- $\beta$-CD was applied to modify the bare GCE. The performance of modified GCE was investigated by cyclic voltammetry $(\mathrm{CV})$. Interestingly, the performance of GCE modified by SWCNTs- $\beta$-CD conjugation was better than that of GCE modified by the hybrids of $\beta$-CD/SWCNTs under identical conditions. FTIR, TGA as well as HRTEM were employed to characterize the titled product. To the best of our knowledge, there is no report on the modification of GCE with $\beta$-CD covalently functionalized SWCNTs.

\section{Experimental}

\subsection{Materials}

SWCNTs with a purity of $60 \mathrm{wt} \%$ were obtained from Shenzhen Nanotech Port Co., Ltd. (Shenzhen, China), which were prepared by the chemical vapor deposition (CVD) method. $\beta$-CD was purchased from Sigma-Aldrich. $\mathrm{p}$-Toluenesulfonyl (p-TsCl), 1,6-Hexanediamine (HDA) were chemical grade. Freshly prepared AA and UA solutions prior to measurements were used. All other reagents and solvents were purchased from commercial suppliers and used as received.

\subsection{Oxidation of SWCNTs}

In a typical experiment, a round bottom flask was charged with $200 \mathrm{mg}$ of SWCNTs and cooled in an ice bath. Then, $20 \mathrm{~mL}$ of concentrated $\mathrm{H}_{2} \mathrm{SO}_{4} / \mathrm{HNO}_{3}$ (3:1 by volume) was slowly added. The mixture was subjected to sonication at $0^{\circ} \mathrm{C}$ for $30 \mathrm{~min}$. The flask was stirred for 20 $\mathrm{h}$ at $20^{\circ} \mathrm{C}$. The dispersion was then carefully poured into $1000 \mathrm{~mL}$ of deionized water. The black slurry was vacuum filtered on a $0.22 \mu \mathrm{m}$ Teflon membrane, resulting in the formation of a black filter cake. The black filter cake was then subjected to dispersion by sonication and rinsed with deionized water until the $\mathrm{pH}$ value of the filtrate was neutral. The product was dried under vacuum.

\subsection{Preparation of Mono-6-(hexanediamino)- $\beta$-cy-clodextrin (HDA- $\beta$-CD)}

HDA- $\beta$-CD was prepared by two successive chemical processes. Firstly, Mono-6-OTs- $\beta$-CD was synthesized according to the method reported in the literature [38]. In a typical experiment, $\beta$-CD $(30.0 \mathrm{~g}, 26.4 \mathrm{mmol})$ was suspended in $250 \mathrm{~mL}$ of water, and $10 \mathrm{~mL} \mathrm{NaOH}$ aqueous solution $\left(8.2 \mathrm{~mol} \cdot \mathrm{L}^{-1}\right)$ was added dropwise over $1 \mathrm{~h}$. When the suspension became homogeneous slightly yellow solution, $15 \mathrm{~mL}$ of $\mathrm{p}$ - $\mathrm{TsCl}$ acetonitrile solution (13.2 $\left.\mathrm{mol} \cdot \mathrm{L}^{-1}\right)$ was added dropwise over $2 \mathrm{~h}$. This process resulted in the formation of a white precipitate. After $2 \mathrm{~h}$ of stirring at $25^{\circ} \mathrm{C}$, the precipitate was removed by filtration under reduced press and the filtrate was refrigerated overnight at $4^{\circ} \mathrm{C}$. The resulting white precipitate was recrystallized from deionized water and dried under vacuum. ${ }^{1} \mathrm{H}$ NMR $\left(400 \mathrm{MHz}, \mathrm{CDCl}_{3}\right): \delta=7.42-7.45(2 \mathrm{H}$, $\left.=\mathrm{CH}_{\text {meta }}\right), 7.74-7.77\left(2 \mathrm{H},=\mathrm{CH}_{\text {ortho }}\right), 2.42\left(3 \mathrm{H}, \mathrm{CH}_{3}\right)$, 3.83 - 3.68 (28H; C(3)-H, C(6)-H, C(5)-H), $3.51-3.25$ $(14 \mathrm{H} ; \mathrm{C}(2)-\mathrm{H}, \mathrm{C}(4)-\mathrm{H})$; IR $\left(\mathrm{KBr}, \mathrm{cm}^{-1}\right): 3382,2927$, $1029,1320$.

The preparation of HDA- $\beta$-CD was performed as described by Liu, et al. [39]. In a typical experiment, $5.0 \mathrm{~g}$ of Mono-6-OTs- $\beta$-CD $(3.8 \mathrm{mmol})$ and $10.0 \mathrm{~g}(0.17 \mathrm{~mol})$ of HAD were charged into a bottom flask equipped with a condenser. The mixture was stirred at $75^{\circ} \mathrm{C}$ for $4 \mathrm{~h}$, and then the mixture was allowed to cool to room temperature. Subsequently, $300 \mathrm{~mL}$ of cold acetone was added, resulting in the formation of a precipitate. The obtained precipitate was dissolved in $10 \mathrm{~mL}$ of water-methanol ( $\mathrm{v} / \mathrm{v} 3: 1)$ mixture, and then poured into $300 \mathrm{~mL}$ of acetone. This operation was repeated several times for the complete removal of unreacted HAD. The obtained sam- 
ple was dried at $50^{\circ} \mathrm{C}$ for $72 \mathrm{~h}$ in a vacuum oven. ${ }^{1} \mathrm{H}$ NMR $\left(400 \mathrm{MHz}, \mathrm{CDCl}_{3}\right): \delta=4.90(7 \mathrm{H}, \mathrm{C}(1)-\mathrm{H}), 3.83-$ 3.68 (28H; C(3)-H, C(6)-H, C(5)-H), $3.51-3.25(14 \mathrm{H}$; $\mathrm{C}(2)-\mathrm{H}, \mathrm{C}(4)-\mathrm{H}), 2.89\left(2 \mathrm{H},-\mathrm{CH}_{2} \mathrm{NH}-\beta-\mathrm{CD}\right), 1.57-$ $1.38\left(8 \mathrm{H},-\left(\mathrm{CH}_{2}\right)_{4}-\right)$. IR $\left(\mathrm{KBr}, \mathrm{cm}^{-1}\right): 3382,2927,1050$.

\subsection{Preparation of $\beta$-CD Covalently Functionalized SWCNTs (SWCNTs- $\beta$-CD)}

SWCNTs- $\beta$-CD was prepared by two successive chemical processes. In a typical experiment, $20 \mathrm{mg}$ of oxidated SWCNTs and $30 \mathrm{~mL}$ of fresh $\mathrm{SOCl}_{2}$ were added to a round-bottom flask with a condenser and reacted at $65^{\circ} \mathrm{C}$ for $24 \mathrm{~h}$ under magnetic stirring. After cautious removal of the residual $\mathrm{SOCl}_{2}$ under reduced press, $20 \mathrm{~mL}$ dried DMF and $5.0 \mathrm{~g}$ of HDA- $\beta$-CD were quickly added, and the flask was immersed in $60^{\circ} \mathrm{C}$ oil bath for another $72 \mathrm{~h}$ enduration with continuous stirring. The dispersion was vacuum filtered on a $0.22 \mu \mathrm{m}$ Teflon membrane and left a black filter cake. The black filter cake was then subjected to dispersion by sonication and rinsed with the deionized water repeated. After centrifugation, the collected crude product was dried in vacuum to give a black solid of the SWCNTs- $\beta$-CD.

\subsection{Analysis and Characterization}

FTIR spectra were recorded on a PE Spectrum One FTIR spectrometer with $\mathrm{KBr}$ pellets. 1HNMR spectra were recorded on a Bruker AV-400 NMR spectrometer in deuterated solvents. Thermogravimetric analysis (TGA) was carried out on a STA 449C instrument under a flowing nitrogen atmosphere. Transmission electron microscopy (TEM) analysis was performed on a JEOL 2100 electron microscope. All the voltammetric experiments were carried out with a CHI-660B electrochemical workstation (Shanghai, China). A conventional threeelectrode system was employed, comprising a GCE (3 $\mathrm{mm}$, diameter) as working electrode, a platinum wireascounter electrode, and a saturated calomel electrode as reference electrode.

\section{Results and Discussion}

\subsection{Synthesis of SWCNTs- $\beta$-CD}

The synthesis of SWCNTs- $\beta$-CD was accomplished as depicted in Scheme 1. SWCNTs were first oxidized by concentrated $\mathrm{H}_{2} \mathrm{SO}_{4} / \mathrm{HNO}_{3}$ (3:1 by volume). This process resulted in the incorporation of carboxyl groups on the surface of SWCNTs.

The introduction of carboxylic acid groups onto the SWCNT surface was verified by the appearance of a carboxyl stretch at $1719 \mathrm{~cm}^{-1}$ as well as a carboxylate ion stretch at $1620 \mathrm{~cm}^{-1}$ in the FTIR spectrum of the oxidized product [40], as shown in Figure 1B. Subsequently, the carboxylic acid-functionalized tubes were activated with $\mathrm{SOCl}_{2}$ followed by treatment with $\mathrm{HDA}-\beta-\mathrm{CD}$, yielding SWCNTs- $\beta$-CD. The introduction of $\beta$-CD on the surface of SWCNTs was proved by the appearance of an $-\mathrm{C}-\mathrm{O}-\mathrm{C}-$ stretch at $1030 \mathrm{~cm}^{-1},-\mathrm{CONH}-$ stretch at $1550 \mathrm{~cm}^{-1}$ as well as $-\mathrm{CH}_{2}-$ stretch at $2987 \mathrm{~cm}^{-1}$ in the FTIR spectrum (Figure 1C) [39].

The obtained SWCNTs- $\beta$-CD could be well dispersed in the water. Figure 2 showed three vials containing equal volume of solvent of water and equal mass of pure SWCNTs (vial A), SWCNTs- $\beta$-CD (vial B) and $2 \mathrm{wt} \%$ $\beta$-CD aqueous solution dispersed SWCNTs (vial C). Clearly, SWCNTs is all completely insoluble in water, whereas SWCNTs- $\beta$-CD in vial B formed a clear, darkbrown solution that contained no discernable particulate materials, and remains stable for a period of at least four weeks. The dispersion formed by $2 \mathrm{wt} \% \beta$-CD aqueous solution dispersed SWCNTs in vial C was instability, and the SWCNTs completely aggregated in $72 \mathrm{~h}$.

The content of $\beta$-CD on the surface of SWCNTs was analyzed by TGA instrument, and the result was indicated in Figure 3. For comparison, the TGA plot of pristine SWCNTs and oxidiated SWCNTs were also shown in Figure 3. If using the mass loss of the SWCNT- $\mathrm{COOH}$ at $500^{\circ} \mathrm{C}$ as the reference, the mass loss of SWCNTs- $\beta$-CD was about $8 \mathrm{wt} \%$ at $500^{\circ} \mathrm{C}$.

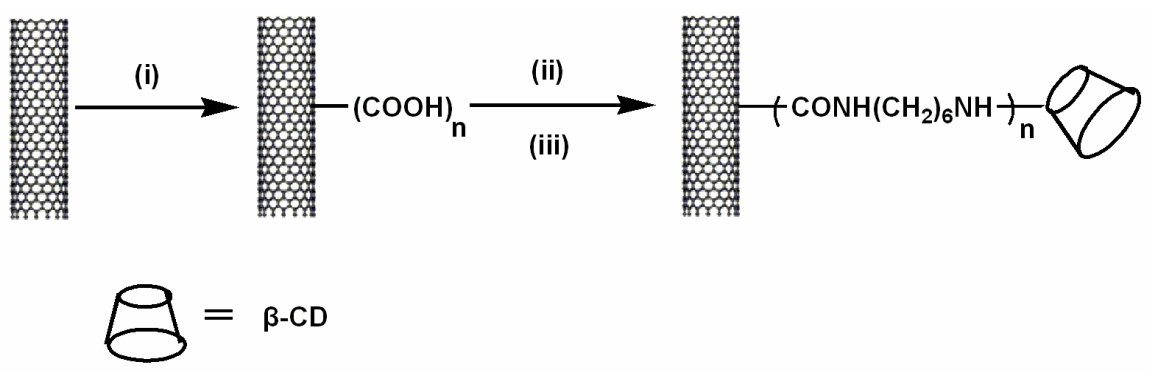

Conditions: (i) $\mathrm{H}_{2} \mathrm{SO}_{4} / \mathrm{HNO}_{3}(3: 1), 20^{\circ} \mathrm{C}, 20 \mathrm{~h}$; (ii) $\mathrm{SOCl}_{2}, 65^{\circ} \mathrm{C}, 24 \mathrm{~h}$; (iii) $\beta-\mathrm{CD}, \mathrm{DMF}, 60^{\circ} \mathrm{C}, 72 \mathrm{~h}$

Scheme 1. The synthesis protocol of SWCNTs- $\beta$-CD. 


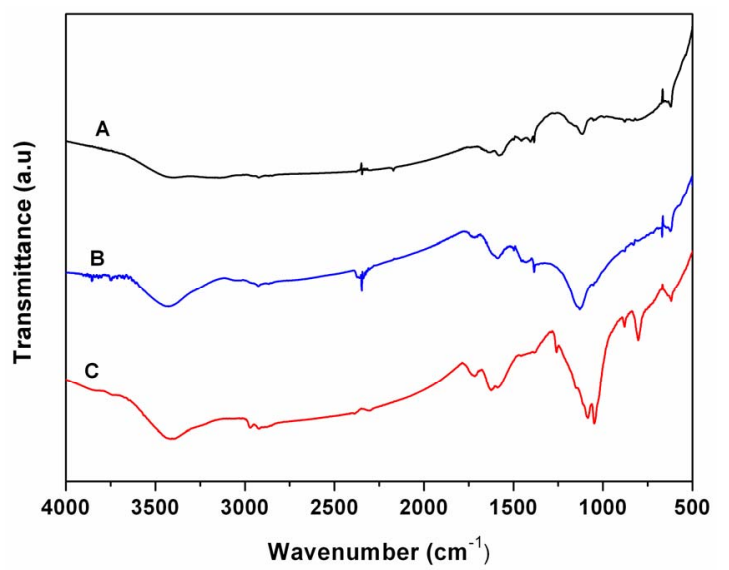

Figure 1. FTIR spectra of the pristine SWCNTs (A), SWCNT-COOH (B), and SWCNTs- $\beta$-CD (C).

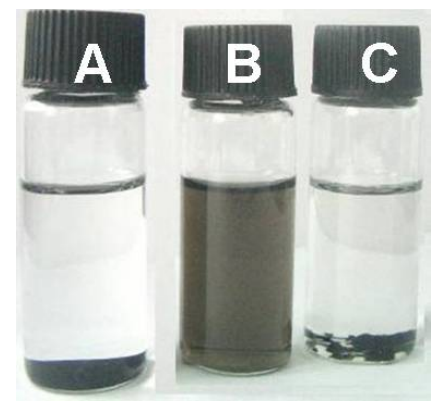

Figure 2. Photograph of three separate SWCNTs samples in water: (A) SWCNTs; (B) SWCNTs- $\beta$-CD; (C) 2 wt\% $\beta$-CD aqueous solution dispersed SWCNTs after $72 \mathrm{~h}$.

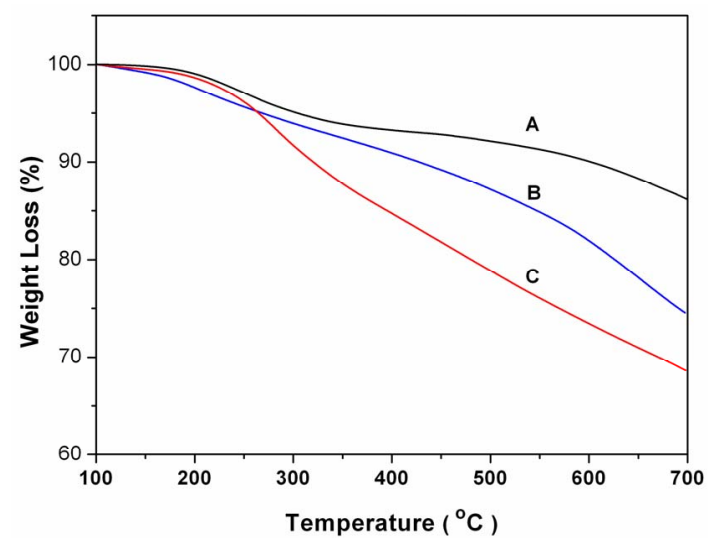

Figure 3. TGA plots of the pristine SWCNTs (A), SWCNTCOOH (B), SWCNTs- $\beta$-CD (C), acquired under nitrogen at

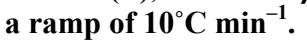

The morphology of SWCNTs- $\beta$-CD was imaged by a high resolution TEM, as depicted in Figure 4. Based on TEM observation, SWCNTs bundle have been exfoliated to small bundles, even individual tube. $\beta$-CDs were grafted on the tips as well as sidewalls of the SWCNTs,
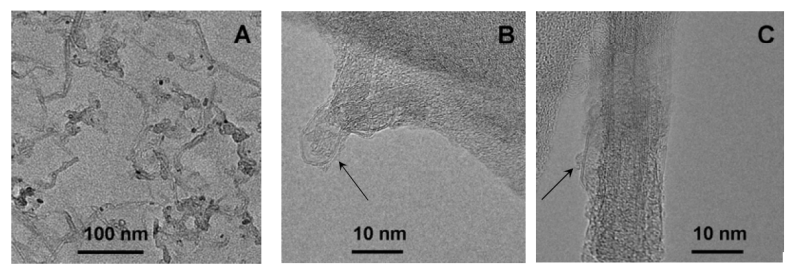

Figure 4. Representative TEM images of SWCNTs- $\beta$-CD.

which did not form a uniform coating layer on the surface of exfoliated SWCNTs.

\subsection{Electrochemical Sensor of $A A$ and $U A$ by SWCNTs- $\beta$-CD Modified GCE}

The GCE with a diameter of $3 \mathrm{~mm}$ was firstly treated by standard procedure. And then, the modification of GCE was accomplished by coating $5 \mu \mathrm{L}$ of SWCNTs- $\beta$-CD solution of water $\left(0.5 \mathrm{mg} \cdot \mathrm{mL}^{-1}\right)$ onto the surface of fresh treated GCE. As a control, $1 \mathrm{mg}$ of pristine SWCNTs was dispersed in $2 \mathrm{~mL}$ of $2 \mathrm{wt} \% \beta$-CD aqueous solution by ultrasonication, and then the dispersion was also applied to modify GCE. The modified GCEs were marked with SWCNTs- $\beta$-CD/GCE and SWCNTs/ $\beta-\mathrm{CD} / \mathrm{GCE}$, respectively. The performances of modified GCEs were evaluated by $\mathrm{CV}$ method, where AA and UA were selected as a prelimiltary substrate. CVs for the AA and UA mixture $\left(1.0 \mathrm{mmol} \cdot \mathrm{L}^{-1} \mathrm{AA}+1.0 \mathrm{mmol} \cdot \mathrm{L}^{-1} \mathrm{UA}\right)$ in PBS ( $\mathrm{pH} 7.0)$ at the bare GCE and at the modified GCEs were shown in Figure 5. It could be observed that, in the case of bare electrode, the voltammograms of AA and UA exhibited just a small hump peak with the overlapping potential. No cathodic peaks were observed for both AA and UA, which indicated an electrochemically irreversible process (curve A). In the case of SWCNTs- $\beta$ $\mathrm{CD} / \mathrm{GCE}$, however, two well-distinguished anodic peaks at potentials of 8 and $379 \mathrm{mV}$ were observed, corresponding to the oxidation of AA and UA, respectively, (curve B). Worth noticing is that the anodic peak potential difference between AA and UA is approximately 371 $\mathrm{mV}$, which is much bigger than early reported methods [41-43]. This suggested the electron transfer on the modified GCE was facilitated. Additionally, substantial increases in peak currents were also observed (curve B), and the anodic current value of UA at the modified electrode is much higher than that of AA. The reason for this phenomenon may originate from the high concentration of UA in the interface of modified electrode due to the selective inclusion effect of $\beta$-CD. Since $\beta$-CD can readily include the neutral UA than AA monoanionic species at $\mathrm{pH} 7.0$ [44]. Compared with curve $\mathrm{B}$, the peak currents of $\mathrm{AA}$ and UA at SWCNTs/ $\beta$-CD/GCE (curve C) was smaller than that of SWCNTs- $\beta$ - CD/GCE, and its oxida 


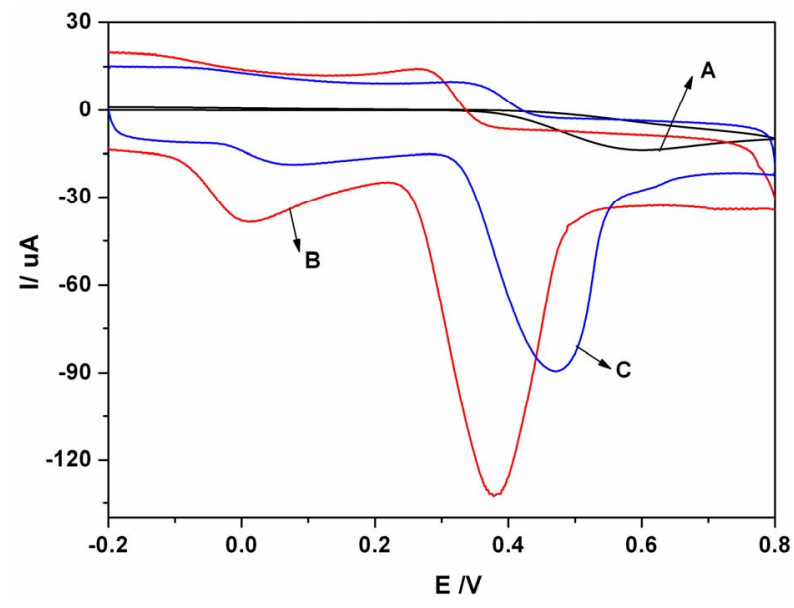

Figure 5. Cyclic voltammograms for the mixture of $1.0 \times$ $10^{-3} \mathrm{~mol} \cdot \mathrm{L}^{-1}$ of $A A$ and $1.0 \times 10^{-3} \mathrm{~mol} \cdot \mathrm{L}^{-1}$ of $U A$ in $0.1 \mathrm{~mol} \cdot \mathrm{L}^{-1}$ pH 7.0 PBS at (A) the bare GCE, (B) SWCNTs- $\beta$-CD/GCE, (C) SWCNT / $\beta$-CD/GCE. Scan rate: $50 \mathrm{mV} \cdot \mathrm{s}^{-1}$.

tive potentials shifted positively. This phenomenon might be deriving from the reduced electron transfer rate on electrode due to the continuous $\beta$-CDs layer absorbed on the surface of SWCNTs. The experimental results demonstrated that SWCNTs- $\beta$-CD colud be utilized to construct a good sensor platform.

\section{Conclusions}

$\beta$-CD covalently functionalized SWCNTs has been prepared. TEM demonstrated that SWCNTs bundle was exfoliated into smaller bundle, even individual tube. The introduced $\beta$-CD components were not uniformly coated on the surface of SWCNTs. This morphology of SWCNTs- $\beta$-CD was benefited for the electron transfer when SWCNTs- $\beta$-CD was utilized to modify the GCE. For the selected prelimiltary substrates of AA and UA, CV measurements indicated that the anodic peak potential difference between AA and UA was approximately $371 \mathrm{mV}$ on the SWCNTs- $\beta$-CD modified GCE, which was larger than that of the GCE modified by the hybrids of $\beta$-CD/SWCNTs under the identical condition. This suggested the electron transfer was hampered on the hybrids of $\beta$-CD/SWCNTs modified GCE due to the insulated $\beta$-CD layer absorbed on the surface of SWCNTs.

\section{Acknowledgements}

Financial support from Program for NCET (NCET-070731), NSFC (51072172), Key Project of Chinese Ministry of Education (209086), Scientific Research Fund of Hunan Provincial Education Department (08B085), Open Project Program of Key Laboratory of Advanced Functional Polymeric Materials of Hunan Province (AFPM200904) and the Planned Science and Technology Pro- ject of Hunan Province (2010WK2009) is greatly acknowledged.

\section{REFERENCES}

[1] S. Iijima, "Helical Microtubules of Graphitic Carbon," Nature, Vol. 354, No. 6348, 1991, pp. 56-58. doi: $10.1038 / 354056 \mathrm{a} 0$

[2] M. M. J. Treacy, T. W. Ebbesen and J. M. Gibson, "Exceptionally High Young's Modulus Observed for Individual Carbon Nanotubes," Nature, Vol. 381, No. 6584, 1996, pp. 678-680. doi:10.1038/381678a0

[3] T. W. Odom, J. L. Huang, P. Kim and C. M. Lieber, "Atomic Structure and Electronic Properties of Singlewalled Carbon Nanotubes," Nature, Vol. 391, No. 6662 , 1998, pp. 62-64. doi:10.1038/34145

[4] N. Ferrer-Anglada, V. Gomis, Z. EI-Hachemi, U. Dettlaff Weglikovska, M. Kaempgen and S. Roth, "Carbon Nanotube Based Composites for Electronic Applications: CNT Conducting Polymers, CNT-Cu," Physica Status Solidi A, Vol. 203, No. 6, 2006, pp. 1082-1087. doi:10.1002/pssa.200566188

[5] V. Bliznyuk, S. Singamaneni, R. Kattumenu and M. Atashbar, "Surface Electrical Conductivity in Ultrathin Single-Wall Carbon Nanotube/Polymer Nanocomposite Films," Applied Physics Letters, Vol. 88, No. 16, 2006, pp. 164101-164103. doi:10.1063/1.2193812

[6] E. Itoh, I. Suzuki and K. Miyairi, "Field Emission from Carbon-Nanotube-Dispersed Conducting Polymer Thin Film and Its Application to Photovoltaic Devices," Japanese Journal of Applied Physics, Vol. 44, No. 1, 2005, pp. 636-640. doi:10.1143/JJAP.44.636

[7] D. H. Zhang, M. A. Kandadai, J. Cech and S. A. Curran, "Poly(l-lactide)(PLLA)/Multiwalled Carbon Nanotube (MWCNT) Composite: Characterization and Biocompatibility Evaluation," Journal of Physics and Chemistry, Vol. 110, No.26, 2006, pp. 12910-12915. doi:10.1021/jp061628k

[8] A. Thess, R. Lee and P. Nikolaev, et al., "Crystalline Ropes of Metallic Carbon Nanotubes," Science, Vol. 273, No. 5274, 1996, pp. 483-487. doi:10.1126/science. 273.5274 .483

[9] C. Journet, W. K. Maser and P. Bernier, et al, "LargeScale Production of Single-Walled Carbon Nanotubes by the Electric-Arc Technique," Nature, Vol. 388, No. 4, 1997, pp. 756-758. doi:10.1038/41972

[10] B. R. Priya and H. J. Byrne, "Investigation of Sodium Dodecyl Benzene Sulfonate Assisted Dispersion and Debundling of Single-Wall Carbon Nanotubes," Journal of Physics and Chemistry C, Vol. 112, No. 2, 2008, pp. 332-337. doi:10.1021/jp0743830

[11] H. Murakami, T. Nomura and N. Nakashima, "Noncovalent Porphyrin-Functionalized Single-Walled Carbon Nanotubes in Solution and the Formation of Porphyrin-Nanotube Nanocomposites," Chemical Physics Letters, Vol. 378, No. 5-6, 2003, pp. 481-485. doi:10.1016/S0009-2614(03)01329-0 
[12] H. Kong, C. Gao and D. Yan, "Controlled Functionalization of Multiwalled Carbon Nanotubes by in Situ Atom Transfer Radical Polymerization," Journal of the American Chemical Society, Vol. 126, No. 2, 2004, pp 412-413. doi:10.1021/ja0380493

[13] T. Morishita, M. Matsushita, Y. Katagiri and K. Fukumori, "Synthesis and Properties of Macromer-Grafted Polymers for Noncovalent Functionalization of MultiWalled Carbon Nanotubes," Carbon, Vol. 47, No. 11, 2009, pp. 2716-2726. doi:10.1016/j.carbon.2009.05.032

[14] Y. Zhang, H. K. He, C. Gao and J. Y. Wu, "Covalent Layer-by-Layer Functionalization of Multiwalled Carbon Nanotubes by Click Chemistry," Langmuir, Vol. 25, No. 10, 2009, pp. 5814-5824. doi:10.1021/la803906s

[15] M. Yang, Y. Gao, H. Li and A. Adronov, "Functionalization of Multiwalled Carbon Nanotubes with Polyamide 6 by Anionic Ring-Opening Polymerization," Carbon, Vol. 45, No. 12, 2007, pp. 2327-2333. doi:10.1016/j.carbon.2007.07.021

[16] Y. Gao, G. Song, A. Alex and H. M. Li, "Functionalization of Single-Walled Carbon Nanotubes with Poly(methyl methacrylate) by Emulsion Polymerization," Journal of Physics and Chemistry C, Vol. 114, No. 39, 2010, pp. 16242-16249. doi:10.1021/jp104894a

[17] Z. Guo, L. Liang and J. J. Liang, et al, "Covalently $\beta$-Cyclodextrin Modified Single-Walled Carbon Nanotubes: A Novel Artificial Receptor Synthesized by 'Click' Chemistry," Journal of Nanoparticle Research, Vol. 10, No. 6, 2008, pp. 1077-1083. doi:10.1007/s11051-007-9338-z

[18] G. Neelgund and A. Oki, "Pd Nanoparticles Deposited on Poly(lactic acid) Grafted Carbon Nanotubes: Synthesis, Characterization and Application in Heck C-C Coupling Reaction," Applied Catalysis A: General, Vol. 399, No.1-2, 2011, pp.154-160. doi:10.1016/j.apcata.2011.03.050

[19] D. Pantarotto, C. D. Partidos and J. Hoebeke, et al., "Immunization with Peptide-Functionalized Carbon Nanotubes Enhances Virusspecific Neutralizing Antibody Responses," Chemistry and Biology, Vol. 10, No. 10, 2003, pp. 961-966. doi:10.1016/j.chembiol.2003.09.011

[20] K. Shi, T. C. Jessop, P. A. Wender and H. Dai, "Nanotube Molecular Transporters: Internalization of Carbon Nanotube-Protein Conjugates into Mammalian Cells," Journal of the American Chemical Society, Vol. 126, No. 22, 2004, pp. 6850-6851. doi:10.1021/ja0486059

[21] D. Pantarotto, R. Singh and D. McCarthy, et al., "Functionalised Carbon Nanotubes for Plasmid DNA Gene Delivery," Angewandte Chemie, Vol. 116, No. 39, 2004, pp.5354-5358. doi:10.1002/ange.200460437

[22] K. Nikolaos, P. Rigini M and S. Argiris, et al., "Peptidomimetic-Functionalized Carbon Nanotubes with Antitrypsin Activity," Carbon, Vol. 47, No. 15, 2009, pp. 3550-3558. doi:10.1016/j.carbon.2009.08.025

[23] T. Loftsson and M. E. Brewster, "Pharmaceutical applications of cyclodextrins.1. Drug solubilization and stabi- lization," Journal of Pharmaceutical Sciences, Vol. 85, No. 10, 1996, pp. 1017-1025. doi:10.1021/js950534b

[24] R. A. Rajewskix and V. J. Stella, "Pharmaceutical Applications of Cyclodextrins 2. in Vivo Drug Delivery," Journal of Pharmaceutical Sciences, Vol. 85, No. 11, 1996, pp. 1142-1169. doi:10.1021/js960075u

[25] Y. Liu and Y. Chen, "Cooperative Binding and Multiple Recognition by Bridged Bis(b-cyclodextrin)s with Functional Linkers", Accounts of Chemical Research, Vol. 39, No. 10, 2006, pp. 681-691. doi:10.1021/ar0502275

[26] R. Villalonga, R. Cao and A. Fragoso, "Supramolecular Chemistry of Cyclodextrins in Enzyme Technology," Chemical Reviews, Vol. 107, No. 7, 2007, pp. 3088-3116. doi:10.1021/cr050253g

[27] Y. Chen and Y. Liu, "Cyclodextrin-Based Bioactive Supramolecular Assemblies," Chemical Society Reviews, Vol. 39, No. 2, 2010, pp. 495-505. doi:10.1039/b816354p

[28] S. A. Nepogodiev and J. F. Stoddart, "CyclodextrinBased Catenanes and Rotaxanes," Chemical Reviews, Vol. 98, No. 5, 1998, pp. 1959-1976. doi: $10.1021 / \mathrm{cr} 970049 \mathrm{w}$

[29] A. Harada, "Cyclodextrin-Based Molecular Machines," Accounts of Chemical Research, Vol. 34, No. 6, 2001, pp. 456-464. doi:10.1021/ar0001741

[30] G. Wenz, B. H. Han and A. Müller, "Cyclodextrin Rotaxanes and Polyrotaxanes," Chemical Reviews, Vol. 106, No. 3, 2006, pp. 782-817. doi:10.1021/cr970027+

[31] H. Tian and Q. C. Wang, "Recent Progress on Switchable Rotaxanes," Chemical Society Reviews, Vol. 35, No. 4, 2006, pp. 361-374. doi:10.1039/b512178g

[32] A. Harada, Y. Takashima and H. Yamaguchi, "Cyclodextrin-Based Supramolecular Polymers," Chemical Society Reviews, Vol. 38, No. 4, 2009, pp. 875-882. doi: $10.1039 / \mathrm{b} 705458 \mathrm{k}$

[33] K. Michael and R. Helmut, "Supramolecular Gels Based on Multi-Walled Carbon Nanotubes Bearing Covalently Attached Cyclodextrin and Water-Soluble Guest Polymers," Macromol. Rapid Commun, Vol. 29, No. 14, 2008, pp. 1208-1211. doi:10.1002/marc.200800142

[34] S. Kang, Z. Cui and L. Liu, et al., "Sensitizing Effect of Oxazine on the Photoluminescence of Cyclodextrin-Modified Carbon Nanotubes," Journal of Dispersion Science and Technology, Vol. 27, No. 1, 2006, pp. 45-47. doi:10.1081/DIS-200066711

[35] Q. Jiang, H. Zhang and Y. liu, "Solvent-Controlled Photoinduced Electron Transfer between Porphyrin and Carbon Nanotubes," Journal of Organic Chemistry, Vol. 73, No 6. 2008, pp. 2163-2168. doi:10.1021/jo702400k

[36] P. Liang, H. Y. Zhang, Z. L. Yu and Y. Liu, "Preparation and Characterization of Soluble Methyl-B-Cyclodextrin Functionalized Single-Walled Carbon Nanotubes," Physica E, Vol. 40, No. 3, 2008, pp. 689-692. doi:10.1016/j.physe.2007.09.082

[37] Y. Yang, C. Tsui and C.Tang, et al., "Functionalization of Carbon Nanotubes with Biodegradable Supramolecular 
Polypseudorotaxanes from Grafted-Poly(e-caprolactone) and $\alpha$-cyclodextrins", European Polymer Journal, Vol. 46, No. 2, 2010, pp.145-155. doi:10.1016/j.eurpolymj.2009.10.020

[38] R. C. Petter, J. S. Salek, C. T. Sikorski, R. C. Petter, J. S. Salek, C. T. Sikorski, G. Kumaravel, and F. T. Lin, "Cooperative Binding by Aggregated Mono-6-(alkylamino)$\beta$-Cyclodextrins," Journal of the American Chemical Society, Vol. 112, No. 10, 1990, pp. 3860-3868. doi:10.1021/ja00166a021

[39] Y. Y. Liu, X. D. Fan and L. Gao, "Synthesis and Characterization of $\beta$-Cyclodextrin Based Functional Monomers and Its Copolymers with N-isopropylacrylamide," Macromolecular Bioscience, Vol. 3, No. 12, 2003, pp. 715719. doi:10.1002/mabi.200300052

[40] J. Liu, A. G. Rinzler and H. Dai, et al., "Fullerene Pipes," Science, Vol. 280, No. 5367, 1998, pp. 1253-1256. doi:10.1126/science.280.5367.1253

[41] M. C. Rodriguez, J. Sandoval, L. Galicia, S. Gutierrez and G. A. Rivas, "Highly Selective Determination of Uric Acid in the Presence of Ascorbic Acid at Glassy Carbon
Electrodes Modified with Carbon Nanotubes Dispersed in Polylysine," Sensors and Actuators B, Vol. 134, No. 2, 2008, pp. 559-565. doi:10.1016/j.snb.2008.05.035

[42] Y. X. Li and X. Q. Lin, "Simultaneous Electroanalysis of Dopamine, Ascorbic Acid and Uric Acid by Poly(vinyl alcohol) Covalently Modified Glassy Carbon Electrode," Sensors and Actuators B, Vol. 115, No. 1, 2006, pp. 134-139. doi:10.1016/j.snb.2005.08.022

[43] S. G. Wu, T. L. Wang, Z. Y., H. H. Xu, B. N. Zhou and C. Wang, "Selective Detection of Uric Acid in the Presence of Ascorbic Acid at Physiological pH by Using a $\beta$-cyclodextrin Modified Copolymer of Sulfanilic Acid and N-Ace-Tylaniline," Biosensors and Bioelectronics, Vol. 23, No. 12, 2008, pp. 1776-1780. doi:10.1016/j.bios.2008.02.012

[44] L. Z. Zheng, S. G. Wu, X. Q. Lin, L. Nie and L. Rui, "Selective Determination of Uric Acid by Using a $\beta$-Cyclodextrin Modified Electrode," Electroanalysis, Vol. 13, No. 16, 2001, pp. 1351-1354.

doi:10.1002/1521-4109(200111)13:16<1351::AID-ELAN $1351>3.0 . \mathrm{CO} ; 2-\mathrm{F}$ 